\title{
ĐĂC ĐIỂM LÂM SÀNG GIẢM CHÚ Ý Ở TRË RỐI LOẠN TĂNG ĐộNG GIẢM CHÚ Ý
}

\section{TÓM TĂT.}

Đă̆t vấn đề: Rối loạn tăng động giảm chú ý ( $A D H D$ ) là một rối loan tẩm thân phổ biển ở trẻ em. Biểu hiện giảm chú ý trong rối loạn tăng động giảm chú ý đảa dang nhưng khó nhân thấy dẫn đến châm chẩn đoán ở trẻ từ đó ảnh hưởng tới hiệu quả điều trị cũng như chất lượng cuộc sống của trẻ. Mục tiêu: Mồ tả đặc điểm lâm sàng giảm chú ý ở trẻ rổi loạn tăng động giảm chú ý. Đối tượng và phương pháp nghiên cứu: Nghiên cứu mô tả cắt ngang 85 trẻ được chẩn đoán ADHD theo tiêu chuẩn DSM $-\mathrm{V}$ tại Bệnh viện Nhi Trung ương từ tháng 8/2020 đến tháng 8/2021. Kết quả: Triệu chứng dể bị sao nhãng bới các kích thích bên ngoài và gặp khó khăn trong việc duy trì sự chú ý trong các nhiệm vụ hoặc hoạt động chiếm tỷ lệ cao nhất 88,2\%; trẻ bị kích thích bởi âm thanh hơn hình ảnh chiếm $60,0 \%$; trẻ chỉ tập trung vào thứ mình thích chiếm $86,7 \%$; triêuu chứng không làm theo hướng dẫn và không hoàn thành việc học, công việc, hoặc nhiệm vụ tại nơi làm việc thì gặp phần lớn trong việc học (97\%); triệu chứng né tránh, không thích hoặc không muốn tham gia vào các nhiệm vụ đòi hỏi phải duy trì nỗ lực tinh thân cũng gặp phần lớn trong việc học $(96,9 \%)$; triệu chứng mất những thứ cân thiết cho các nhiệm vụ hoặc hoạt động thì gặp phần lớn là đánh mất đồ dưng học tập $(92,6 \%)$; triều chứng quên trong các hoạt động hàng ngày, việc quển đồ dùng học tập chiếm 94,3\%. Kết luận: Triệu chứng dễ bị sao nhãng bởi các kích thích bên ngoài chiếm tỷ lệ cao nhất, trẻ dễ dàng bị kích thích bởi âm thanh. Mặc dù trẻ gặp khó khăn trong việc duy trì sự chú ý trong các nhiệm vụ nhưng trẻ lại có khả nẳng tập trung vào thứ mình thích. Trẻ đa phân né tránh việc học, đánh mất đồ dùng học tập,quên đồ dùng học tập.

Tư khóa: giảm chú ý, rối loạn tăng động giảm chú ý.

\section{SUMMARY}

\section{CHARACTERISTICS OF INATTENTION SYMPTOMS IN CHILDREN WITH ADHD}

Background: Attention deficit hyperactivity disorder (ADHD) is one of the children's most common mental disorders. Inattention symptoms are challenging to be realized, leading to delayed diagnosis, affecting the quality of children's lives. Objectives: Describe the characteristics of inattention symptoms in children with ADHD. Subjects and methods: Cross-sectional study of 85 children with ADHD according to DSM-V diagnostic criteria were

\section{aĐại học Y Hà Nọi}

bviên Sức Khỏe Tâm Thần-Bênh Viên Bach Mai

Chịu trách nhiệm chính: Nguyễn Thị Anh Thoa

Email: nguyenthianhthoa.7.1@gmail.com

Ngày nhận bài: 30.7.2021

Ngày phản biên khoa học: 29.9.2021

Ngày duyệt bài: 7.10.2021

\section{Nguyễn Thị Anh Thoa ${ }^{\mathrm{a}}$, Trần Nguyễn Ngọa $\mathrm{a}^{\mathrm{a}, \mathrm{b}}$}

treated from $8 / 2020$ to $8 / 2021$ in Vietnam National Children's Hospital. Results: The symptom of being easily distracted by extraneous stimuli and difficulty sustaining attention in tasks or play activities was the most symptom $(88,2 \%)$; children were more stimulated by sounds than images $(60,0 \%)$; children only focus on which they like $(86,7 \%)$; not following instructions and not completing homework, work, or tasks at homework was the most common symptom $(97,0 \%)$; avoids, dislikes, or is reluctant to engage in tasks that require sustained the mental effort were found almost of the learning $(96,9 \%)$; losing things necessary for tasks or activities were found in the loss of school materials $(92,6 \%)$; forgetting in daily activities, forgetting school materials (94,3\%).

Keywords: Inattention, ADHD.

\section{I. ĐĂT VẤN ĐỀ}

Rối loạn tăng động giảm chú ý là một rối loạn tâm thân phổ biến ở trẻ em. Theo Thomas và cộng sự (2015) ước tính tỷ lệ mắc rối loạn này trên toàn thế giới ở trẻ từ 18 tuổi trở xuống là 7,2\% [1]. Rối loạn đặc trưng bởi ba nhóm triệu chứng giảm chú ý và hoặc tăng động - xung động, khởi phát trước 12 tuổi, tôn tại ở từ hai môi trường khác nhau trở lên (ví dụ: gia đình, trường học, nơi làm việc, với bạn bè hoặc người thân,trong các hoạt đông khác...) [2].

Trẻ có rối loạn tăng động giảm chú ý đối diện với rất nhiều vấn đề trong quá trình phát triển tâm sinh lý, trong học tập cũng như trong cuộc sống. Biểu hiện giảm chú ý trong rối loạn tăng động giảm chú ý cũng đa dạng nhưng khó nhận thấy dẫn đến chậm chẩn đoán ở trẻ từ đó ảnh hưởng tới hiệu quả điều trị cũng như chất lượng cuộc sống của trẻ [3].

Nghiên cứu sâu về đặc điểm lâm sàng giảm chú ý ở trẻ rối loạn tăng động giảm chú ý nhằm hỗ trợ công tác chẩn đoán và điều trị đảm bảo cho trẻ có được cuộc sống tốt đẹp. Vì vậy chúng tôi tiến hành nghiên cứu với mục tiêu: Mô tả đặc điểm lâm sàng giảm chú ý ở trẻ rôi loạn tăng động giảm chú ý.

\section{II. ĐỐI TƯỢNG VÀ PHƯƠNG PHÁP NGHIÊN CỨU}

2.1 Đối tượng nghiên cứu: Nghiên cứu 85 trẻ được chẩn đoán ADHD theo tiêu chuẩn DSM -V khám ngoại trú tại Bệnh viên Nhi Trung ương từ tháng 8/2020 đến tháng 8/2021.

Tiêu chuẩn lựa chọn:

- Bệnh nhân được chẩn đoán xác định mắc rối loạn tăng động giảm chú ý theo tiêu chuẩn 
của DSM- V tới khám lần đầu.

Tiêu chuẩn loại trừ:

- Bệnh nhân không có người nhà cung cấp tư liệu chính xác và khách quan về tiền sử, bệnh sử của bệnh nhân.

- Bệnh nhân có bệnh thực tổn não, các bệnh cơ thể nặng. Loại trừ các bệnh nhân có tổn thương thực thể các cơ quan phát âm, thị giác, thính giác. Trẻ có các rối loạn vận động tự động trong các bệnh lý nội khoa thần kinh: múa giật, múa vờn, run, loạn trương lực cơ.

- Những bệnh nhân không tự nguyện tham gia nghiên cứu, hoặc người nhà không đồng ý hợp tác nghiên cứu.

\subsection{Phương pháp nghiên cứu:}

- Nghiên cứu mô tả cắt ngang với cách chọn mẫu thuận tiện. 20.0 .

- Nhập và xử lý số liệu bằng phần mềm SPSS

2.3 Đạo đức nghiên cứu: Nghiên cứu không can thiệp, mục đích giúp đánh giá đầy đủ và điều trị hiệu quả hơn cho bệnh nhân và chỉ tiến hành khi có sự đồng ý của bệnh nhân và người nhà. Nghiên cứu được hội đồng thông qua đề cương nghiên cứu Trường Đại học Y Hà Nội, hội đồng đạo đức $Y$ học Bệnh viện nhi Trung Ương thông qua.

\section{KẾT QUẢ NGHIÊN CỨU}

Bảng 1: Đặc điểm chung của đôî̉ tượng nghiên cứu

\begin{tabular}{|c|c|c|c|}
\hline \multicolumn{2}{|c|}{ Đặc điểm } & $\begin{array}{c}\text { Số } \\
\text { lượng }\end{array}$ & $\begin{array}{c}\text { Tỷ lệ } \\
\text { (\%) }\end{array}$ \\
\hline \multirow{2}{*}{ Giới } & Nam & 73 & 85,9 \\
\cline { 2 - 4 } & Nữ & 12 & 14,1 \\
\hline \multirow{2}{*}{$\begin{array}{c}\text { Nhóm } \\
\text { tuổi }\end{array}$} & $2-5$ & 9 & 10,6 \\
\cline { 2 - 4 } & $6-10$ & 74 & 87,0 \\
\cline { 2 - 4 } & $>10$ & 2 & 2,4 \\
\hline \multicolumn{2}{|c|}{ Tuối khởi phát trung bình } & $4,41 \pm 1,61$ \\
\hline
\end{tabular}

Nhận xét: Tỷ lệ nam: nữ = 6:1, tuối hay gặp nhất là nhóm tuổi từ 6-10 tuổi chiếm: 87,1\%\%; tuổi khởi phát trung bình là 4,41 $\pm 1,61$.

Bảng 2: Tỷ lệ triệu chứng giảm chú ý

\begin{tabular}{|c|c|c|c|}
\hline \multicolumn{2}{|c|}{ Chỉ số nghiên cứu } & Số lượng & Tỷ lệ (\%) \\
\hline \multirow{2}{*}{$\begin{array}{l}\text { Chú ý } \\
\text { quá } \\
\text { chuyển } \\
\text { động }\end{array}$} & $\begin{array}{c}\text { Không thể chú ý kỹ lưỡng vào các chi tiết hoặc phạm những } \\
\text { những lỗi do cẩu thả trong học tập, trong công việc hoặc } \\
\text { trong các hoạt động khác }\end{array}$ & 70 & 82,4 \\
\hline & Dễ bị sao nhãng bởi các kích thích bên ngoài & 75 & 88,2 \\
\hline \multirow[b]{2}{*}{$\begin{array}{l}\text { Chú ý } \\
\text { suy yếu }\end{array}$} & Dường như không lắng nghe khi được nói chuyện trực tiếp & 64 & 75,3 \\
\hline & $\begin{array}{c}\text { Gặp khó khăn trong việc duy trì sự chú ý trong các nhiệm vụ } \\
\text { hoặc hoạt động }\end{array}$ & 75 & 88,2 \\
\hline \multirow{5}{*}{$\begin{array}{l}\text { Hậu quả } \\
\text { của } \\
\text { giảm } \\
\text { chú ý }\end{array}$} & $\begin{array}{l}\text { Không làm theo hướng dẫn và không hoàn thành việc học, } \\
\text { công việc, hoặc nhiệm vụ tại nơi làm việc }\end{array}$ & 67 & 78,8 \\
\hline & Gặp khó khăn trong việc tổ chức các nhiệm vụ và hoạt động & 61 & 71,8 \\
\hline & $\begin{array}{c}\text { Né tránh, không thích hoặc không muốn tham gia vào các } \\
\text { nhiệm vụ đòi hỏi phải duy trì nỗ lực tinh thần }\end{array}$ & 64 & 75,3 \\
\hline & $\begin{array}{l}\text { Mất những thứ cân thiết cho các nhiệm vụ hoặc hoạt động } \\
\text { (đồ dùng học tập: bút, sách vở, thước, tẩy) }\end{array}$ & 54 & 63,5 \\
\hline & Quên trong các hoạt động hàng ngày & 53 & 62,4 \\
\hline
\end{tabular}

Nhân xét: Triệu chứng dễ bi sao nhãng bởi các kích thích bên ngoài và gặp khó khăn trong việc duy trì sự chú ý trong các nhiệm vụ hoặc hoạt động chiếm tỷ lệ cao nhất 88,2\%.

Các triệu chứng không thể chú ý kỹ lưỡng vào các chi tiết hoặc phạm những những lỗi do cẩu thả trong học tập; trong công việc hoặc trong các hoạt động khác; không làm theo hướng dẫn và không hoàn thành việc học, công việc, hoặc nhiệm vụ tại nơi làm việc; né tránh, không thích hoăc không muốn tham gia vào các nhiệm vụ đòi hỏi phải duy trì nỗ lực tinh thần; dường như không lắng nghe khi được nói chuyện trực tiếp; gặp khó khăn trong việc tổ chức các nhiệm vụ và hoạt động; mất những thứ cần thiết cho các nhiệm vụ hoặc hoạt động (đồ dùng học tập: bút, sách vở, thước, tẩy); quên trong các hoạt động hàng ngày chiếm tỷ lệ khá cao lần lượt là $82,4 \%$; $78,8 \% ; 75,3 \%$; 75,3\%; 71,8\%; 63,5\%; 62,4\%.

Bảng 3: Đặc điểm triệu chứng giảm chú ý

\begin{tabular}{|c|c|c|c|}
\hline \multicolumn{2}{|c|}{ Chỉ số nghiên cứu } & Số lượng & Tỷ lệ (\%) \\
\hline Không thể chú ý kỹ lưỡng vào các & Viết nhảy cóc từ & 22 & 31,4 \\
\hline
\end{tabular}


VIETNAM MEDICAL JOURNAL N²2 - OCTOBER - 2021

\begin{tabular}{|c|c|c|c|}
\hline \multirow{4}{*}{$\begin{array}{c}\text { chi tiết hoăc phạm những những } \\
\text { lỗi do cẩu thả trong học tập, } \\
\text { trong công việc hoặc trong các } \\
\text { hoạt động khác }\end{array}$} & Đọc lướt qua & 36 & 51,4 \\
\hline & Hoàn thành công việc nhanh cho xong & 46 & 65,7 \\
\hline & Mắc lô̂i dại dột ở trường & 46 & 65,7 \\
\hline & Mắc lỗi dại dột ở nhà & 42 & 60,0 \\
\hline \multirow{3}{*}{$\begin{array}{l}\text { Dễ bị sao nhãng bởi các } \\
\text { kích thích bên ngoài }\end{array}$} & Bị kích thích bởi âm thanh hơn & 45 & 60,0 \\
\hline & Bị kích thích bởi hình ảnh hơn & 6 & 8,0 \\
\hline & $\begin{array}{c}\text { Kích thích bởi âm thanh và hình ảnh } \\
\text { bằng nhau }\end{array}$ & 24 & 32,0 \\
\hline \multirow{2}{*}{$\begin{array}{l}\text { Dường như không lắng nghe khi } \\
\text { được nói chuyện trực tiếp }\end{array}$} & $\begin{array}{c}\text { Không chú ý nghe giảng, lạc vào } \\
\text { thế giới riêng }\end{array}$ & 64 & 100 \\
\hline & $\begin{array}{c}\text { Không giao tiếp bằng mắt, nhìn vào } \\
\text { khoảng không }\end{array}$ & 51 & 79,7 \\
\hline \multirow{2}{*}{$\begin{array}{c}\text { Gặp khó khăn trong việc duy trì } \\
\text { sự chú ý trong các nhiệm vụ } \\
\text { hoặc hoạt động }\end{array}$} & Khó tiếp nhận thông tin từ bên ngoài & 51 & 68,0 \\
\hline & Chỉ tập trung vào thứ mình thích & 65 & 86,7 \\
\hline \multirow{2}{*}{$\begin{array}{l}\text { Không làm theo hướng dẫn và } \\
\text { không hoàn thành việc học, công } \\
\text { việc, hoặc nhiệm vụ tại nơi làm việc }\end{array}$} & Việc học & 65 & 97,0 \\
\hline & Việc chơi & 28 & 41,8 \\
\hline \multirow{3}{*}{$\begin{array}{l}\text { Gặp khó khăn trong việc tổ chức } \\
\text { các nhiệm vụ và hoạt động }\end{array}$} & Quản lí thời gian & 49 & 80,3 \\
\hline & Lập kế hoạch & 22 & 36,1 \\
\hline & Quên cuộc hẹn & 26 & 42,6 \\
\hline \multirow{2}{*}{$\begin{array}{l}\text { Né tránh, không thích hoặc không } \\
\text { muốn tham gia vào các nhiệm vụ } \\
\text { đòi hỏi phải duy trì nô̂ lực tinh thân }\end{array}$} & Việc học & 62 & 96,9 \\
\hline & Việc nhà & 16 & 25,0 \\
\hline \multirow{2}{*}{$\begin{array}{l}\text { Mất những thứ cân thiết cho các } \\
\text { nhiệm vụ hoặc hoạt động (đồ dùng } \\
\text { học tập: bút, sách vở, thước, tẩy) }\end{array}$} & Đồ dùng học tập & 50 & 92,6 \\
\hline & Đồ chđ̛i & 22 & 40,7 \\
\hline \multirow{2}{*}{$\begin{array}{c}\text { Quên trong các hoạt động hàng } \\
\text { ngày }\end{array}$} & Đồ dùng học tập & 50 & 94,3 \\
\hline & Đồ chơi & 17 & 32,1 \\
\hline
\end{tabular}

Nhận xét: Biểu hiện hoàn thành công việc nhanh cho xong và mắc lỗi dại dột ở trường chiếm tỷ lệ cao nhất dều là 65,7\%.Các biểu hiện mắc lỗi dại dột ở nhà, đọc lướt qua, viết nhảy cóc từ, viết chậm có tỷ lệ lần lượt là: $60,0 \%$; $51,4 \% ; 31,4 \% ; 14,3 \%$.

Trẻ dễ bị kích thích bởi âm thanh hơn hình ảnh chiếm 60,0 . Không chú ý nghe giảng, lạc vào thế giới riêng chiếm tỷ lệ tuyệt đối 100.Đa phần trẻ chỉ tập trung vào thứ mình thích $(86,7 \%)$.

Phần lớn gặp khó khan trong việc học $(97 \%)$, né tránh việc học $(96,9 \%)$, đánh mất đồ dùng học tập (92,6\%), quên đồ dùng học tập (94,3\%).

\section{BÀN LUÂN}

Nghiên cứu về đặc điểm chung của đối tượng cho thấy nghiên cứu của chúng tôi gặp chủ yếu ở nam giới $(85,9 \%)$. Kết quả này phù hợp với một số nghiên cứu trên thế giới rằng $A D H D$ chủ yếu gặp ở nam giới, theo Torunn Stene Nøvik (2006) tỷ lệ nam giới mắc ADHD trong nhóm nghiên cứu 1478 trẻ chiếm 84,3\% [4]. Tuổi khởi phát trung bình là $4,41 \pm 1,61$ tuổi. Kết quả này tương đồng với kết quả nghiên cứu của Mark $A$. Riddle (2013) với tuổi khởi phát trung bình là 4,1 tuổi [5].

Về tỷ lệ của triệu chứng giảm chú ý kết quả của chúng tôi chỉ ra rằng triệu chứng dễ bị sao nhãng bởi các kích thích bên ngoài và gặp khó khăn trong việc duy trì sự chú ý trong các nhiệm vụ hoăc hoạt động chiếm tỷ lệ cao nhất $88,2 \%$. Đặc điểm này tương đồng với nghiên cứu của Timothy J. Silk (2019) [6].

Trẻ thường hoàn thành công việc nhanh cho xong mà không để ý đến chất lượng cũng như hay mắc những lỗi dại dột ở trường. Trẻ thường dễ bị sao nhãng bởi các kích thích âm thanh hơn các kích thích hình ảnh. Đặc điểm triệu chứng hậu quả của giảm chú ý cũng như việc mắc những lỗi dại dột ở trường trẻ né tránh, không thích hoăc không muốn tham gia vào việc hoc, phần lớn đánh mất đồ dùng học tập, cũng như quên đồ dùng học tập. Geoff Kewley cũng đã chỉ 
ra rằng phần lớn các triệu chứng của trẻ đều xoay quanh việc học, việc làm bài tập về nhà là rất khó khan do nhiều lí do để né tránh như đi vệ sinh, gọt bút chì, cũng chính vì không tập trung trong việc học trẻ hay đánh mất và quển đồ dùng học tập của mình [7].

\section{KẾT LUẬN}

Qua nghiên cứu 85 trẻ được chẩn đoán ADHD nhận thấy: rối loạn chủ yếu gặp ở nam giới. Tuổi chẩn đoán hay gặp ở nhóm tuổi 6-10 tuổi. Triệu chứng dễ bị sao nhãng bởi các kích thích bển ngoài chiếm tỷ lệ cao nhất, trẻ dễ dàng bị kích thích bởi âm thanh. Mặc dù trẻ gặp khó khăn trong việc duy trì sự chú ý trong các nhiệm vụ nhưng trẻ lại có khả năng tập trung vào thứ mình thích. Trẻ đa phần né tránh việc học, đánh mất đồ dùng học tập, quên đồ dùng học tập.

TÀl LIỆU THAM KHẢO

1. Thomas R., Sanders S., Doust J. và cộng sự.
(2015). Prevalence of attention-deficit/ hyperactivity disorder: a systematic review and meta-analysis. Pediatrics, 135(4), e994-1001.

2. (2013), Diagnostic and statistical manual of mental disorders: DSM-5 ${ }^{\mathrm{TM}}$, 5th ed, American Psychiatric Publishing, Inc., Arlington, VA, US.

3. Martin A., Volkmar F.R., và Bloch M.H. (2017), Lewis's Child and Adolescent Psychiatry: A Comprehensive Textbook, Wolters Kluwer Health.

4. Nøvik T.S., Hervas A., Ralston S.J. và cộng sứ. (2006). Influence of gender on attentiondeficit/hyperactivity disorder in Europe--ADORE. Eur Child Adolesc Psychiatry, 15 Suppl 1, I15-24.

5. Riddle M.A., Yershova K., Lazzaretto D. và cộng sự. (2013). The Preschool AttentionDeficit/Hyperactivity Disorder Treatment Study (PATS) 6-year follow-up. ] Am Acad Child Adolesc Psychiatry, 52(3), 264-278.e2.

6. Silk T.J., Malpas C.B., Beare R. và cộng sự. (2019). A network analysis approach to ADHD symptoms: More than the sum of its parts. PLOS ONE, 14(1), e0211053.

7. Kewley G. (2006), Attention Deficit Hyperactivity Disorder: What Can Teachers Do?, Routledge, London.

\section{TẮC RUộT QUAI ĐÓNG: GIÁ TRỊ CHẨN ĐOÁN CỦA CẮT LỚP VI TÍNH ĐA DÃY}

\section{TÓM TẮT.}

Mục tiêu: đánh giá giá trị của cắt lớp vi tính (CLVT) đa dãy trong chẩn đoán tắc ruột quai đóng (TRQĐ). Phương pháp: 145 bệnh nhân tắc ruột trong đó có 40 bệnh nhân TRQĐ được xác định bằng phẩu thuật đã được chụp CLVT có tiêm thuốc cản quang trước mổ tại bệnh viện Việt Đức từ tháng 7/2019 đến tháng 4/2021. Hai bác š̃ chẩn đoán hình ảnh không biết trước kết quả phâ̂u thuật xem phim CLVT và đánh giá 11 dấu hiệu trên CLVT. Từ đó đánh giá độ nhạy, độ đặc hiệu, giá trị dự đoán dương tính và giá tri dự đoán âm tính của từng dấu hiệu. Kết quá: Chẩn đoán TRQĐ, dấu hiệu có ít nhất hai điểm chuyển tiếp có độ nhạy $100 \%$, độ đặc hiệu $97,1 \%$. Dâu hiệu mỏ chim có độ nhạy $87,5 \%$, độ đặc hiệu $66,7 \%$. Dâu hiệu quai ruột hình chữ $U /$ chữ $C$, quai ruột giãn nằm ở vị trí bất thường trong ổ bưng có đô đặc hiêu $100 \%$ và độ nhạy tương ứng là $32,5 \%$ và $15 \%$.Chấn đoán biến chứng thiếu máu thành ruột, dấu hiêuu thành ruột ngấm thuốc kém có độ nhạy $62 \%$, độ đặc hiệu $94,7 \%$; mạch máu mạc treo ngấm

\footnotetext{
${ }^{1}$ Trường Đại học Y Hà Nội

²Bệnh viện Hữu nghi Việt Đức

Chịu trách nhiệm chính: Phạm Thị Thoa

Email: drphamthithoa@gmail.com

Ngày nhận bài: 2.8.2021

Ngày phản biện khoa học: 30.9 .2021

Ngày duyệt bài: 7.10.2021
}

thuốc kém có độ nhạy 23,8\%, độ đặc hiệu 100\%. Kết luâan: ở những bệnh nhân được khảo sát của chúng tôi, có ít nhất hai điểm chuyển tiếp, quai ruột chữ $U / C$, quai ruột giãn ở vị trí bất thường trong ổ bụng có giá trị cao trong chẩn đoán TRQĐ. Sự giảm ngấm thuốc thành ruột và mạch máu mạc treo tương ứng là dấu hiệu gợi ỳ tốt cho thiếu máu ruột. vi tính.

Tư khóa: tắc ruột, quai đóng, thiếu máu, cắt lớp

\section{SUMMARY \\ CLOSED - LOOP BOWEL OBSTRUCTION: DIAGNOSIS VALUE OF \\ MULTISLICECOMPUTED TOMOGRAPHY}

Purpose: The aim of this study was to determine the value of multislice computed tomography (MSCT) in the diagnosis of closed - loop bowel obstruction (CLBO). Methods: 145 patients with bowel obstruction, including 40 patients with CLBOconfirmed by surgery, had preoperated contrast enhancement CT (CECT) at Viet Duc hospital from July 2019 to April 2021. Two blinded radiologists retrospectively reviewed CECT and evaluated 11 CT findings. The sensitivity, specificity, positive predictive value and negative predictive value of each finding was evaluated. Results: Diagnosis of CLBO, at least two transition points has sensitivityof $100 \%$, specificity of $97.1 \%$. Beak sign has sensitivity of $87.5 \%$, specificity of $66.7 \%$. U/C shape configuration, dilated bowel loop in an abnormal position in the abdomen have specificities of $100 \%$ and sensitivities of $32.5 \%$ and 